\title{
Metodologia ativa além dos limites físicos de uma instituição de ensino superior
}

\author{
Adriano Cândido de Lima1, Cleciana Alves Cruz ${ }^{1}$, Kerma Márcia de Freitas ${ }^{1}$, \\ Tulio Vidal Rolim¹, Renata Pinheiro de Santana ${ }^{1}$, Rita Gabriela de Sousa Muniz ${ }^{1}$, \\ Fernando Antônio Mota Trinta ${ }^{2}$ \\ ${ }^{1}$ Faculdade Vale do Salgado (FVS) \\ Icó - CE - Brasil \\ ${ }^{2}$ Departamento de Computação - Universidade Federal do Ceará (UFC) \\ Fortaleza-CE - Brasil \\ \{adriano, kerma, tuliovidal, renatasantana\} @ fvs.edu.br, \\ \{cleciana.cruz,gabi2014muniz\} @hotmail.com, fernando.trinta@dc.ufc.br
}

\begin{abstract}
The aim of this study was to demonstrate the experience of using the active methodology under discussion that goes beyond the physical limits of the Faculdade Vale do Salgado. A discussion was organized entitled "Selfmedication: Risk or Benefit?" Was organized, being conducted by the professors of the disciplines of Nursing and Physiotherapy, linking the discipline of Applied Informatics to Health of the Faculty of Vale do Salgado and counted on the participation of students and internal and External to the institution. It was noticed through the reports and analysis of the discussions that social networks can be used as a form of promotion, awareness and practice of the contents approached in the classroom.
\end{abstract}

Resumo. Objetivou-se demonstrar a experiência vivida na utilização da metodologia ativa em discussão que ultrapassa os limites físicos da Faculdade Vale do Salgado. Organizou-se um debate intitulado "Automedicação: Risco ou Beneficio?", sendo conduzido pelos professores das disciplinas de Enfermagem e Fisioterapia, vinculando a disciplina de Informática Aplicada à Saúde da Faculdade Vale do Salgado e contou com a participação de alunos e profissionais internos e externos à instituição. Percebeu-se por meio dos relatos e análise das discussões que as redes sociais podem ser utilizadas como forma de promoção, conscientização e prática dos conteúdos abordados em sala de aula.

\section{Introdução}

Percebeu-se, nos últimos anos, a sutil preocupação de profissionais da área da saúde sobre questões relacionadas ao processo de ensinar e aprender. Muitas vezes, a experiência profissional, unicamente, não é formativa. Para ser facilitada, precisa ser atrelada a realidade para transformar-se em saberes diferenciados, estimulando o raciocínio e trazendo um pensamento formador de opinião. Esse tipo de método explora tentativas, experimentos e mudanças nos quais o enfoque principal é estimular o receptor a desenvolver um pensamento crítico, tornando-se um ser ativo (PIVETTA, 2014). 
VI Congresso Brasileiro de Informática na Educação (CBIE 2017)

Anais dos Workshops do VI Congresso Brasileiro de Informática na Educação (WCBIE 2017)

A partir da aprovação da Lei Federal no 9.394, de 20 de dezembro de 1996, foram estabelecidas as Diretrizes e Bases da Educação Nacional no Brasil, percebeu-se uma mudança na área da saúde, tendo em vista que os métodos de formação curriculares necessitavam de inovação. Assim, surgia a necessidade de modificação de métodos de ensino, focando metodologias inovadoras para alcançar as propostas legais (BRASIL, 1996).

Segundo Oliveira et al. (2010) as críticas aos métodos de aprendizagem disponíveis nas Instituições de Ensino Superior (IES) entram em alteração comumente, pois, percebe-se a frequência de mais alunos tornarem-se passivos do ensino, onde o profissional educador ainda é o responsável pelas decisões do ensino transferindo o saber.

A competência ética dos futuros profissionais graduandos em IES de saúde é entendida e esperada através da formação de sua autonomia (da maneira como os mesmos percebem as situações), reflexão crítica e ações coesas em relação às condutas humanas nos cuidados a saúde e de forma geral para com o próximo. $\mathrm{O}$ desenvolvimento desse senso crítico deve ser despertado nos alunos através da competência de docentes preparados e prontos para assumir a responsabilidade sobre discussões relacionadas as práticas educativas, favorecendo uma formação qualificada ao discente, visando a sua atuação em sociedade, mas, para isso, é necessário que o corpo docente se torne desenvolvedor de competências críticas e reflexivas (GERBER; ZAGONEL, 2013).

Além disso, Silva et al. (2015), acrescentam que mesmo tendo o modelo tradicional de ensino como método predominante, após críticas e sistematização de percepções de educação, na área da saúde, estão sendo inseridas outras metodologias.

O discente deve despertar autonomia a partir da forma em que o ensino lhe é transmitida, ou seja, deve desenvolver competências que estão relacionadas com a capacidade do mesmo em solucionar situações complexas que exigem conhecimento, habilidade, experiência e atitudes do próprio. Assim, muito diferente do que integra o ensino tradicional se vê que somente a transmissão de conteúdos não se torna satisfatória para que a formação seja qualificada. É necessário que junto com os conteúdos ministrados sejam feitas também trocas de experiências e habilidades entre educador e educando (BÔAS, 2015).

Com isso, as formas de ensino inovadoras que enfocam a importância da dimensão social e política percebendo que o ambiente de ensino, mais precisamente o espaço acadêmico, deve levar em conta situações e realizar problematizações fazendo com que haja uma ligação entre o ensino e a realidade, realizando uma junção entre os conhecimentos (formal e de vivência) enfocando nas percepções sociais de vivências referidas no ambiente acadêmico, fazendo assim, que o discente possa construir seu próprio conhecimento e pensamento crítico (FREIRE, 2011).

Logo, as metodologias ativas vieram reorganizar e reestruturar a forma de transferência de ensino. Do mesmo modo que as estratégias utilizadas para arquitetar o ensino e seus métodos, precisam de materiais e meios para serem utilizados sobre a conduta do docente e discente concomitantemente desenvolvendo discentes participativos e com posicionamento crítico-reflexivo (OLIVEIRA et al., 2010).

Ainda, o uso das Metodologias Ativas antecipa que ao invés de vários alunos saírem de suas instituições de ensino terem aprendido algo só por ter sido exposto à conteúdos em aulas somente expositivas, terão discentes que tiveram a oportunidade de 
construir conhecimento através de situações de aprendizagem vivenciadas no período de graduação. É através dessas metodologias que se pode desenvolver alunos que tenham verdadeiro prazer na busca por conhecimento (BLIKSTEIN, 2010).

As metodologias ativas estimulam os discentes a relacionar as suas vivências e interagir sobre os assuntos e disciplinas, facilitando o conhecimento, refletindo em uma melhor absorção de informação e, posteriormente, em uma graduação mais qualificada. Este método, mais interativo e inovador, facilita também a aprendizagem graças à imersão de cenários bastante próximos da realidade, o que leva ao discente a refletir sobre as situações, estimulando-o a pensar e desenvolver novos conhecimentos (COSTA et al, 2015).

Diante das Leis de Diretrizes e Bases da Educação Nacional (LDB) as instituições procuram cada vez mais implantarem métodos que possam vir a estimular a articulação entre ensino, pesquisa e assistência, fazendo assim, que métodos de ensino inovadores, interativos e didáticos comecem a ser implantados nessas instituições que possam despertar o interesse do aluno quanto a aprendizagem em sala de aula e ao meio social, mesclando vivências as matérias ministradas em sala de aula (SOBRAL; CAMPOS, 2012).

Assim, viu-se que o uso deste tipo de metodologia era de fundamental importância na formação do pensamento crítico e intelectual dos discentes. Salientando a associação da tecnologia com esse método levando e compartilhando o conhecimento entre acadêmicos e comunidade. Logo, a Faculdade Vale do Salgado implementa essa ideia na associação de teoria e prática de forma interdisciplinar.

Objetivou-se demonstrar a experiência vivida na utilização da metodologia ativa em discussão que ultrapassa os limites físicos da Faculdade Vale do Salgado.

\section{Métodos}

Trata-se de um estudo descritivo, relato de experiência, realizado com os Cursos de Enfermagem e Fisioterapia, vinculando as disciplinas de Informática Aplicada à Saúde e Fundamentos de Farmacologia da Faculdade Vale do Salgado.

A princípio, tinha-se um total 65 alunos das disciplinas envolvidas que deveriam participar de um debate que envolvesse um assunto polêmico e atual. Visando alcançar um número maior de participantes, 15 dias antes da ação os discentes utilizaram a rede social "Facebook" para publicar "banners" e compartilhar avisos acerca do debate, buscando sensibilizar, promover e instigar a participação de todos os interessados na temática. Para melhor controle e organização dos dados pessoais dos integrantes, foi criado um formulário eletrônico de inscrição no aplicativo Kapta (www.kapta.com.br), no ato da inscrição o interessado tinha a possibilidade de adicionar o contato de mais dois convidados.

Constatado que o número de inscrições no debate estava aumentando absurdamente em escala exponencial, foi detectado que seria extremamente complicado acompanhar o decorrer deste, pois seria praticamente impossível acompanhar tantas mensagens ao mesmo tempo, podendo consequentemente prejudicar as discussões entre os participantes, então foi decidido encerrar as inscrições sete dias antes da realização da ação. Tendo em vista que até esse momento já haviam sido inscritos profissionais dessas e de outras áreas, acadêmicos de saúde de diversos municípios, sendo a maior parte 
destes das regiões do Vale do Salgado e Cariri, além de outros estados, logo com o número exorbitante de participantes não seria possível desenvolver a ideia proposta.

Para melhor entendimento sobre o decorrer do debate, um dia antes da realização da atividade foi enviada a todos os participantes inscritos uma mensagem contendo as informações e regras sobre como este seria organizado.

No dia da ação todos os membros foram adicionados ao grupo do aplicativo "WhatsApp" com uma antecedência de uma hora, proporcionando melhor organização e diminuindo a chance de possíveis imprevistos. Foi usado como critério a inserção dos membros somente algum tempo antes de iniciar o debate, para diminuir a possibilidade de conversas paralelas que pudessem surgir.

Com duração total de 02 (duas) horas a atividade ocorreu quarta-feira dia 31 de agosto do ano de 2016, através da rede social "WhatsApp" foi formado um grupo constituído por 184 membros. Por meio deste foram propostos 05 (cinco) cenários com situações problema voltados à temática Automedicação: Risco ou Benefício? Os participantes deveriam expor e argumentar através de textos, imagens, áudios ou vídeos seu posicionamento. Foi estipulado como critério de funcionamento que a discussão sobre cada cenário só iria durar no máximo 20 (vinte) minutos.

\section{Resultados e Discussão}

Durante do debate foi possível notar informações e argumentações bem referenciadas e pertinentes. Vários participantes além de expor sua opinião e argumentar em relação a temática proposta no cenário exposto naquele momento, ainda usava citações de importantes fontes científicas como forma de fundamentação da sua afirmação. Houveram várias mensagens em forma de áudio e imagem que contribuíram significativamente com o decorrer do debate, pois através destas, os participantes conseguiam falar de forma mais clara e direta seu posicionamento. Foi perceptível comprometimento e seriedade com o assunto por parte de todos os integrantes.

Vislumbrou-se com muita frequência a utilização da função do aplicativo que faz a citação de mensagens de outros membros do grupo, vários integrantes faziam a menção da opinião do outro como forma de concordar ou discordar, expondo de forma inusitada sua opinião argumentativa utilizando várias fontes da saúde como forma de fundamentar sua posição.

Após a finalização da discussão sobre todos os cenários que durou cerca 1 hora e 50 minutos, foi aberto durante 10 minutos a possibilidade de exposição das opiniões acerca da possível contribuição que a ação teve para sua formação. Observou-se a satisfação destes em dizer que ação muito contribuiu para sua formação e achou a ideia bastante positiva, pois conseguiram esclarecer várias dúvidas que tinham ou que surgiram durante o debate, sendo possível visualizar a automedicação de vários ângulos e ambientes.

\section{Conclusão}

Ao final do debate, percebeu-se por meio dos relatos e análise das discussões, que as redes sociais podem ser utilizadas como forma de promoção, conscientização e prática dos conteúdos teóricos abordados em sala de aula. Pois, através da integração tecnológica, os discentes conseguiram ter a oportunidade de discutir e argumentar seus posicionamentos e opiniões acerca da temática de automedicação. 
Outrora foi possível afirmar com total convicção que a utilização de aplicativos de comunicação com o meio externo atrapalham o aprendizado dentro de sala de aula, mas, com o presente estudo é possível vislumbrar com nitidez a quebra do "tabu" de pensar que não é possível adaptar as tecnologias presentes ao nosso redor como forma de aprendizado para formação profissional.

\section{Referências}

BLIKSTEIN, P. O mito do mau aluno e porque o Brasil pode ser o líder mundial de uma revolução educacional. 25 jul. 2010. Disponível em: $<$ http://www.blikstein.com/paulo/documents/books/BliksteinBrasil_pode_ser_lider_mu ndial_em_educacao.pdf $>$. Acesso em: 23 Maio. 2016.

BÔAS, R. V. V.; MORI, Z. C. S. Metodologias inovadoras: uma nova realidade que desafia a efetividade do direito social fundamental à educação e encontra limite na cidade inteligente (ideal). Revista Unicuritiba edu., Sergipe, v. 3, n. 40, 2015. Disponível em: http://revista.unicuritiba.edu.br/index.php/RevJur/article/view/1361/. Acesso em: 03 set. 2016.

BRASIL. Lei $\mathbf{N}^{\circ}$ 9.394, 20 de dezembro de 1996. Lei de Diretrizes e Bases da Educação Nacional. $\quad$ Disponível em:< http://portal.mec.gov.br/seesp/arquivos/pdf/lei9394_ldbn2.pdf>. Acesso em: 02 set. 2016.

COSTA, R. R. O., et al. O uso da simulação no contexto da educação e formação em saúde e enfermagem: uma reflexão acadêmica. Revista espaço para a saúde, Londrina, v. 16, n. 1, p. 59-65, jan. mar. 2015.

FREIRE, Paulo. Pedagogia da Autonomia: Saberes Necessários à Prática Educativa. 43. ed. São Paulo: Paz e Terra, 2011.

GERBER, V. K. Q.; ZAGONEL, I. P. S. A ética no ensino superior na área da saúde: uma revisão integrativa. Rev. Bioét., Brasília, v. 21, n. 1, p. 168-178, Abr. 2013.

OLIVEIRA, L. R., et al. Metodologias ativas de ensino-aprendizagem e suas convergências com as Tecnologias Digitais de Informação e Comunicação. Universidad Complutense de Madrid, Madrid, Nov. 2010.

PIVETTA, H. M. F.; VOGT, M. S. L.; BADARO, A. F. V. Metodologia do ensino superior: uma experiência na pós-graduação lato sensu em fisioterapia. Cad. Edu. Saúde. São Paulo, v.1, n. 2. 2014.

SILVA, D. K. O.; QUARESMA, V. S. M.; PEREIRA, J. A.; CUNHA, E. R. A arte de educar na área da saúde: experiências com metodologias ativas. Humanidades e Inovação, Palmas, v. 2, n. 1, jan., jul. 2015.

SOBRAL, F. R.; CAMPOS, C. J. G. Utilização de metodologia ativa no ensino e assistência de enfermagem na produção nacional: revisão integrativa. Rev. esc. enferm. USP, São Paulo, v. 46, n. 1, p. 208-218, Fev. 2012. 